\title{
Mobile phone services and UK Higher Education students, what do they want from the library?
}

\author{
Andrew Walsh
}

\begin{abstract}
Student attitudes towards the libraries use of mobile technologies in general, and SMS (text messaging) in particular were investigated using a series of focus groups during Autumn 2009 at the University of Huddersfield. The results suggest that students do not feel that text messaging services would be intrusive or unwelcome and they felt overwhelmingly positive towards services such as overdue reminders direct to their phones. The results also suggest that libraries should concentrate on introducing text messaging based systems initially, with other services likely to be well received only if students can see an obvious and immediate benefit to using them. The research was carried out thanks to the Library and Information Research Group (LIRG) research award, 2009.
\end{abstract}

\section{Introduction}

This paper is based on research carried out at the University of Huddersfield, thanks to the Library and Information Research Group (LIRG) Award 2009. Using a series of focus groups at this typical, mid-sized, Post-1992 Higher Education institution with the UK, the research aimed to discover student attitudes towards the potential use of mobile technologies by their University's Library service, particularly, but not exclusively, the use of SMS (text messaging) to deliver services to students. The research was carried out over a short period of time in the Autumn term of the 2009-2010 academic year.

This study primarily used focus groups to examine how readily students would accept mobile friendly services from their library, what services they'd like to see delivered to them via their mobile phones, and whether they would accept contact via SMS as a "default" option, or if they would instead prefer "opt-in" services. Additional supporting information also came from an exit survey of library users.

\section{Andrew Walsh}

Andrew Walsh is a librarian (liaising with Law and Accountancy) at the University of Huddersfield and is interested in mobile learning; web 2.0; and information literacy.

Email: a.p.walsh@hud.ac.uk 
The institution where the study was carried out had been investigating and piloting some limited mobile friendly services to students over the academic year prior to the study, some of which were used as examples to inform the discussion within focus groups. The intention, however, was not to look at or assess any particular existing services, but to qualitatively examine the attitudes of students at the institution towards potential mobile friendly services.

Although this uses an individual institution as a case study, the conclusions pull together the attitudes of the students, rather than particular preferences for individual services. These attitudes are primarily an artefact of the general culture of mobile phone use with the students' wider environment, not their institution. As such the general conclusions are most likely to be applicable across other UK institutions, together with those in other European countries, in Australasia and in North America where mobile usage is directly comparable to the UK.

\section{Literature Review}

There is increasing interest in the use of mobile learning technologies, including mobile phones, with a mixture of ideas for quite basic phone usage including contacting the library via SMS ("text a librarian"), for example Herman (2007); quizzes via SMS (packages now available commercially, for instance http://www.m-learning.org/products/m-learning-products.htm); podcasting (Berk et al., 2007; Ronchetti and Stevovic, 2008); and group discussion via SMS to either web 2.0 services such as Jaiku (http://www.jaiku.com/), moblog (http://moblog.net/home/), or Twitter (http://twitter.com/), or custom web sites such as reported by Sillence and Baber (2004). A range of mobile phone services being developed by libraries are reviewed by Buczynski (2008), showing the increasing interest in taking advantage of mobiles in the library context and many potential usages of text messaging services are outlined by Walsh (2009). Much current research, however, focuses on high end devices that are capable of viewing video, or running small programs to deliver interactive content (especially the Apple i-phone and increasingly the open source Android platform from Google). The literature reviews by Hahn (2008) and Kim et al. (2006) make the emphasis on high end devices clear.

Although there are many case studies published in the literature, most focus on the implementation of a technology or service. Many projects have supplied mobile phones or PDAs (personal digital assistants) to trial participants, for instance the ALPS (Assessment and Learning in Practice Settings) project which issued 900 high end mobiles / PDAs to study participants (http://www.hud.ac.uk/hhs/alps/tools.htm). There has therefore been limited study as to the acceptance of students using their own mobile devices in the context of delivery of library services, in particular whether students would see contact initiated from the library via their own mobiles as being intrusive, as opposed to services such as "text a librarian" where the students themselves choose to initiate contact, though Uday Bhaksar and Govindarajulu (2008) report some brief examples of student feedback on using SMS services and Pasanen (2002) describes an early adoption of such services at Helsinki University of Technology. 
There has, however, been research in the commercial sector into contact by companies, particularly promotional contact, with their customers. Some of this can be directly translated into potential uses for our libraries. A recent Finnish study led by Merisavo (2008), found that mobile advertising which recipients perceived to be both useful in regard to context and content was generally well received. Merisavo also looked at issues of control and trust, in other words, do mobile owners feel some sense of intrusion and perhaps powerlessness on account of receiving advertisements from perhaps dubious senders? The study found that as long as messages were perceived as useful, both in relation to information and situation/timing, neither control nor trust were significant factors.

A further, rather more complex study led by Karjaluoto (2008) broadly concurs with some Merisavo's findings, but also brings in "perceived social utility" as an additional driver, or as an extension of the message's usefulness. Another slight difference is that consumer trust, which Merisavo considered relatively unimportant is believed to gradually develop as organisation/consumer interactions increase, and so can "solidify the relationship" thus fostering "mutually beneficial exchange". Also Karjaluoto, drawing upon his earlier 2006 study on demographics (see above), looks at intention in relation to gender, age, education, income, and even household size, and again cites relative youth as increasing the likelihood of a positive predisposition towards mobile marketing. The results from these studies suggest that in libraries, which are normally perceived as a neutral, trustworthy space, are naturally more likely to have text messages seen as acceptable, reinforced in academic libraries, as their key demographics matches those which Karjaluoto found as particularly comfortable with mobile contact in a previous study (Karjaluoto, 2006), that is 16-20 and 2125 in Karjaluoto's study. The element of "usefulness" is one which we will return to later.

The use of SMS "reminders" is also creeping into education in general, with schools, colleges, and universities experimenting with text messages to remind students about deadlines and more. A study by Jones et al. (2008) showed widespread acceptance of text message reminders amongst their students, directly relevant to one possible way libraries may choose to use mobile technologies.

In terms of the potential for libraries to send out messages longer than simple reminders or reservation shelf notices, a cautionary piece of largely French based research has been conducted recently which investigated if and when a saturation point develops beyond which mobile advertising is at best non-efficient or possibly even a source of irritation to recipients (Gauzente et al., 2008). The study found that a complex relationship exists between demographics, how often and for how long people used their mobiles, and the frequency and text length of sent messages, all of which have a bearing as to when this saturation point may be reached. Again though, concurring with the above studies of Karjaluoto and Merisavo, usefulness is the most important factor for SMS adoption. 


\section{Methodology}

The key questions this study addresses are to do with student attitudes and willingness for the library to intrude upon something that may be seen as a very personal tool, that is, their mobile phone. As such it is preferable to take a qualitative approach to gathering much of the data and give the students a chance to discuss and present their feelings on this topic in their own words.

For the study the researcher primarily used focus groups. These are a good way of exploring feelings and expectations with the population studied, with members able to interact with each other and develop ideas that may not be expressed individually. The limitations include the risk of one or two members dominating a group, or people being reluctant to express opinions contradictory to those already given (so a "group-think mentality can arise). The Library, however, uses focus groups regularly and has a long track record of gathering information to improve its services using such groups, along with corresponding experience of moderating these groups to try and reduce some of the key limitations.

Students were recruited across a range of courses based full or part-time at the main university campus, both undergraduate and taught postgraduate. They were invited to small focus groups, with a prize draw for an iPod Nano acting as a small incentive to encourage attendance, in addition to refreshments during each meeting. Recruitment was through advertising the focus groups and associated prize draw via the Library Twitter account; subject team blogs; plasma screens within the library; and student library inductions across all subject areas. Recruiting students was problematic, as was turning an expressed willingness to attend a focus group into actual attendance. Eighteen students in total attended the focus groups.

Five focus groups were held in the Autumn term of the 2009-2010 academic year. The groups were asked to discuss the idea of library contact via SMS to their own mobiles and to think about the issues that arise with this sort of contact. They were then presented with some possible services along with brief explanations and examples were possible. They were asked to discuss whether they felt each service is interesting and useful to them and their peers. Finally in these focus groups they were asked to rank a list of ten potential mobile friendly services in order of priority for development, with the service they felt as a group to be most useful at number one, and the service they see of least utility at number ten. They were also invited at this stage to suggest other potential developments.

The comments and concerns expressed in the focus group were be grouped and analysed to bring out the key concerns and attitudes to library contact via text message (SMS).

One additional piece of data gathering was carried out, a one day exit survey of the Library. This addressed directly the question. "Would students accept contact via SMS as a "default" option, or would they prefer "opt-in" services?", as it was felt initially that this question lends itself to a quantitative approach where we can easily gather large amounts of data to a simple "either / or" question. The researcher stood in the area immediately past the Library exit and exiting users were asked if they'd be happy the library contacting them by text message using 
the details on their student account, or would they prefer to have the choice to "opt-in" to such a service.

\section{Attitudes towards text messaging}

Attitudes towards text messaging from the Library are overwhelmingly positive. There were some concerns with the Library using text messaging services, but these were based around whether the messages would be "useful" or promotional. Only one group brought up the issue of the text messages being potentially intrusive with comments such as "I prefer, I mean, text messages for me are quite personal, they are from friends not institutions..." and "I get annoyed if I get a text message from my network, do you know what I mean? I pull out my phone, see what it is and think, was it really necessary for $\mathrm{O} 2$ to send this right now".

Even the group that raised concerns about the potential intrusiveness of text messaging stated that they'd be happy receiving text messages by default as long as the messages were useful, and ranked text messaging services at third and fourth in desirability, out of ten suggested mobile services. This concept of "usefulness" cropped up again and again in the focus groups, with all groups considering it okay to for their university to introduce text message based services for all students (so offering only an opt-out option, not waiting for users to opt-in), as long as the service was perceived as being "useful". Perceptions of "usefulness" varied slightly between the groups, with some concrete examples below:

"Reminders and things like that would be quite useful."

"I personally wouldn't mind receiving notifications and things, because I'd find it useful."

"I received a message from the university reminding me I was working tomorrow and I found that really useful." (from a student employed on a part-time basis by the university)

"If you booked a room and where being told it was free, that would be okay, But if you were texted by IT to say something's down and that happened frequently then you'd get a bit annoyed".

"If you requested a book and it's come in, it saves you from having to, if you don't have access on your phone, it saves you having to find a computer to find out if your book's come in. If you get a text, you'll know you've got it and if you're out and about you can just pop into the library and pick that book up".

"That's stuff you're actively interacting with the library with, so you've requested a book or booked a room rather than the library cold calling you on your time."

All of the groups agreed that the services where they had already chosen to interact with the Library were where they'd most like to see text message contact. These services included loans (e.g. notices about books being due back, or overdue); their requested items becoming available (so they knew to come into the library and pick them up); and room bookings (to remind them their booking was about to start). In general, these are services currently dealt with by email reminders and it may be that common email reminders could be duplicated by text 
message fairly readily by libraries, which could be fairly confident that if the email notices are perceived as useful, then the text messages are likely to be well received.

At the researcher's request, the issue of whether to target all students, or only those who chose to opt-in, was discussed at length. More concerns were expressed about students potentially missing out than concerns over use of mobile numbers by the university. As long as the service was perceived as useful, all the groups strongly felt that it should be introduced for all students by default. There were concerns repeatedly raised over students missing out if they had to choose themselves whether to subscribe to a text messaging service.

"I can see the people that are more likely to forget their library books are those that are also most likely not to opt-in."

"Think that if you do it, it has to be driven by the library itself. If you offer the option to students, then 9 times out of 10 they won't either through forgetting or just not wanting to do it."

"Think it's important that you guys drive it."

Besides the issue of "usefulness", the only other reservation expressed over all students automatically receiving text messages using the numbers harvested from their student records, is that it should be easy to opt-out if required. The opt-out should also be clear and easy to do, with it being made clear to all students that they would receive text messages and why, with instructions on how to stop them.

"...if you could just be like other services and you could text back "stop", then that would be okay."

The exit survey, at first glance, somewhat contradicted the focus groups, with only $46 \%$ ( $n=150)$ stating they'd be happy the library using existing records to automatically contact all students and 52\% saying they'd prefer to have to choose themselves to "opt-in". This reflected the comments made in the focus groups about any contact having to be seen as useful to library users, so it is believed it was too simplistic to ask a simply yes / no question in the exit survey, with the response being tied tightly to whether they could immediately see text messages being of utility to them, without being given the chance to consider examples.

\section{General feelings about mobile services and the Library}

Some general feelings about using the Library and mobile phones came out of the focus group discussions that were perhaps a little unexpected. They were not initiated by the researcher, but emerged from the general discussions.

- A perception that you only interact with the library in the library. Mobile services are often introduced to help busy students who are thought of as being constantly on the move and needing opportunities to interact with services wherever they are, in whatever small amounts of time they have available. We expect that they may want to use mobile library services on public transport on their way to lectures, or in snatched moments between lectures, or while waiting to be served in a supermarket queue. In this research, however, the comments from the participants frequently implied 
they thought the only place that people would be interested in interacting with the library, was from within the library. For "text a librarian" services comments were made by several participants similar to "...didn't see the point. Obviously there are librarians knocking about all over the place" and "if I go to the library and need to ask someone something...". These ideas cropped up while discussing several potential services, with a potential text message tips service commented on by on participant "...personally I'd prefer like an FAQ thing on a piece of paper..." and another "... if you had it in leaflet form, in an obvious place, like in the middle of the room...". This perception seemed to persist across all the groups to some extent, with a rather unexpected attitude that although we were discussing mobile services, that users would primarily use them only when they choose to come into the library. This may mean that we should be cautious extrapolating some of the results of this research to part-time, distance learning, or collaborative provision students that rarely visit the campus.

- A reluctance to use the mobile web. More than half (55\%) of focus group participants had accessed email or the general mobile web on their phones, but seemed reluctant to use mobile internet access unless they had a concrete reason for doing so. It was seen as difficult and potentially costly by several participants with comments such as "depends who's paying for it" and "if it's through your phone it can cost a fortune". It may be that even as mobile internet access becomes easier and more widespread and costs come down (charges are already normally capped at a fairly low cost per day, even on pay as you go plans), the perception of mobile internet access as costly and difficult may persist for a time.

- When a potential service manages to meet a perceived need, they are enthusiastic about using it, immediately contradicting points 1 and 2 above. One particular potential service was mobile search of Library services, with a mobile version of Summon (the search tool for electronic resources) shown. Many of the participants were quite enthusiastic about this potential service, suggesting uses for it outside the library through their own mobile phones, despite previously expressing reluctance towards accessing the mobile web, or for accessing mobile friendly library services in general outside the library building.

- There was little sense of the desire to explore or experiment with new services. Some potential services, such as QR codes were described as potentially being useful, even "futuristic", but there was no element within the groups of the desire to experiment or explore these services unless they were already convinced of the services usefulness to them. This is likely to provide a significant barrier to any new service, as we cannot rely on our users to try new services without first persuading them they will find it useful. The very nature of new services, however, means it is hard to do this, we really want them to find out for themselves, allowing us to then fine-tune services and persuade others based on current users. 


\section{Potential services}

A range of potential mobile phone services, pre-prepared by the researcher, was discussed and demonstrated (where possible) and each focus group discussed their feelings about these potential services, as well as being asked about any other potential services they'd like to see developed. They were also asked, as groups, to rank these potential services in order of priority for development with number one as most desirable. The ranking for each focus groups was combined by simply using the rank for each group as a score and adding them together, the potential service with the lowest score was then ranked first. The overall, combined ranking for the potential services was:

1. Reminders by text (for example for overdue items).

2. Search from a mobile device (to easily search the catalogue or electronic resources)

3. Renewals by text (text a central number to automatically renew all items borrowed)

4. More mobile friendly web pages (to be more accessible from mobile devices)

5. Help by text message (a "text a librarian" service)

6. Tips by text message (a series of text messages to support inductions or information skills)

7. Vodcasts (video materials, but in mobile friendly formats)

8. Podcasts (audio materials easily downloadable to mobile devices)

9. QR codes (codes that can be read using freely available applications on mobile phones and used to link to further information, web resources and contact details, amongst other things.)

10. Bluetooth (to automatically recognise users as they walk through the library and deliver appropriate materials or alerts to their mobile phone)

11. There was one additional suggestion from one group, being able to search one shelf at a time from a mobile device within the library, which they ranked 2nd choice.

The rankings were broken down as shown in Table 1 below: 


\begin{tabular}{|l|l|l|l|l|l|l|}
\hline & $\begin{array}{l}\text { Group } \\
\text { A }\end{array}$ & $\begin{array}{l}\text { Group } \\
\text { B }\end{array}$ & $\begin{array}{l}\text { Group } \\
\text { C }\end{array}$ & $\begin{array}{l}\text { Group } \\
\text { D }\end{array}$ & $\begin{array}{l}\text { Group } \\
\text { E }\end{array}$ & $\begin{array}{l}\text { Overall } \\
\text { Ranking }\end{array}$ \\
\hline Reminders by text & 1 & 4 & 1 & 3 & 1 & 1 \\
\hline $\begin{array}{l}\text { Search from a mobile } \\
\text { device }\end{array}$ & 3 & 3 & 6 & 2 & 2 & 2 \\
\hline Renewals by text & 2 & 7 & 2 & 4 & 3 & 3 \\
\hline $\begin{array}{l}\text { More mobile friendly web } \\
\text { pages }\end{array}$ & 8 & 1 & 5 & 1 & 4 & 4 \\
\hline Help by text message & 7 & 5 & 3 & 7 & 5 & 5 \\
\hline Tips by text message & 6 & 6 & 4 & 8 & 7 & 6 \\
\hline Vodcasts & 4 & 10 & 7 & 5 & 6 & 7 \\
\hline Podcasts & 5 & 9 & 8 & 7 & 8 & 8 \\
\hline QR codes & 9 & 5 & 10 & 6 & 10 & 9 \\
\hline Bluetooth & 10 & 11 & 9 & 10 & 9 & 10 \\
\hline Searching by shelf & x & 2 & x & x & x & \\
\hline
\end{tabular}

Table 1: Preference for potential mobile phone services expressed by focus groups $(1=$ most wanted $)$

\subsection{Reminders by text}

This service was by far the most popular, with three out of five of the groups putting it as their first choice. This was the service that was seen to have concrete benefits in all the group discussions and one that most closely matched the sort of service they'd like every student to automatically receive unless they decided to opt-out, with all groups seeing this as being convenient and valuable to all students who use the library. Suggested uses for reminders included when borrowed items were due back, when a requested item was available to be collected, and when a group room the user had booked became available.

\subsection{Search from a mobile device}

This potential service caused some excitement in the groups, with some unexpected suggestions on how they thought it would be of use. Although the general feeling in the groups was that they were reluctant to connect to the internet via mobile phones, there was an immediate feeling in most groups that they would make an exception for this. The researcher expected that this sort of mobile search may be used when library users were travelling or otherwise have small amounts of time to spare. Some participants reinforced this expectation: 
"I commute a lot and print off a lot of journal articles to read on the train. If I could read them on my phone, that would be really useful - I wouldn't have to print it off and pay for it, as well as it being more accessible."

“you wouldn't have to come all the way here just to see if there was a book in."

However, an unexpected suggestion that came independently from two groups was the use in lectures to look up references immediately when mentioned by the lecturer:

"I'd probably use that quite often in lectures. When a lecturer recommended a book I'd pull out my phone and maybe add it to a list or something to use it later on."

"If you're sitting in a lecture and wanted to see what journals were available later, then it would be useful."

Another, somewhat unexpected suggestion, was its use within the library to save walking the short distances to fixed library catalogues, with several groups stating it would be really convenient to have while browsing the shelves or studying within the library:

"Sometimes, when I'm in the library, if I'm sitting down in the music section, then the library catalogue computers are near, like, the stairs, so to check if there's a book in, like, I'd have to go all the way there, but if I could access it where I am then that would make things a lot easier."

\subsection{Renewals by text}

This was seen as valuable by all groups and often linked together with "reminders by text" during their discussions. It was narrowly beaten in the group rankings by "search from a mobile device" as there was some suggestions within the groups that it is so easy to renew books already (the university library allows renewals via the catalogue, by phone (voice), using self-service machines, or in person), that it didn't give as much benefit to the user as mobile search would.

\subsection{More mobile friendly web pages}

Quite realistically, this was discussed at length in various groups as being a necessary precursor to other mobile friendly services. If the Library web pages aren't mobile friendly, then it was seen as pointless to produce other mobile friendly resources as it would be too hard to navigate to them.

"They have to be more mobile friendly before you can do the others."

This seemed to be the key reason for placing this service so highly, not because there was any desire to view the normal Library web pages in mobile friendly formats, but because it was a necessary step for users to be able to find and access some of the other services.

\subsection{Help by text message}

While the other potential services above were generally seen as positive and often discussed enthusiastically, this service (fifth in the ranking) and below were often 
seen as lacking relevance to library users. While it was generally seen as a good, convenient service, many participants couldn't see why it would be useful. Some illustrative comments were listed above, showing that many students thought of themselves as only wanting to ask questions about the library, or accessing information, whilst in the library. Other comments included:

"If I go into the library and need to ask someone something it's usually more complex than can be answered in a simple text."

There was also a feeling that speed was of the essence when answering text questions, with suggestions of anything up to half a day being acceptable time scales:

“...that's crucial, isn't it? I think 2 hours is unacceptable, more like 5 minutes..."

"...if you texted in the morning and had a reply by midday or whatever, then that would be fast enough to be useful."

All the students in the focus groups come onto the campus regularly, so the lukewarm response to text a librarian type services may be a reflection that they are more likely to ask for help face to face than use other enquiry methods.

\subsection{Tips by text message}

This "drip feeding" of information by text was generally seen as a service that could be useful.

"That's definitely going to work because a little bit of information over a long period is far more likely to sink in."

"There are some people on my course that have hardly been in the library, if you do make them realise how useful it can be pretty early on, then you're going to put them in a better position, because right at the beginning is when they are likely to try new things, when they've just arrived."

"...for first years, a really good idea."

This was tempered by several people in the groups thinking about only wanting information on the library, while in the library. Hence comments such as the one below, essentially asking for a service we already offer, with short library handbooks displayed across the library:

"If you had it in leaflet form, in an obvious place, like in the middle of the room, you could have sections saying what to do..."

"I'd prefer, like, an FAQ thing on a piece of paper"

These mixed views meant some groups struggled to come to a consensus as to the relevance or priority of this service, with it tending to hover around the middle of the list of priorities.

\subsection{Vodcasts and Podcasts}

There were some mixed views on these possible services, including some limited concerns over connection charges, "...coming through a wireless hotspot it's fine, but if it's through your phone it can cost a fortune". 
None of the groups could see why they would want to view video or listen to audio from the library, though there was a slight preference towards video, particularly for showing more complex or confusing areas such as research techniques and search skills, potentially as a replacement for library information skills sessions. There was a definite preference to live streaming of content over downloading material across all groups, with comments including:

"I don't know if a lot of people would go through the process of downloading it, they'd want a quick live thing and having to be transferred onto an iPod or whatever, would end up being more hassle than it's actually worth. I think YouTube live streaming is probably a better way of transfer."

"I've streamed a couple of the videos on my laptop, everyone's used to going on YouTube and everything and videos playing, but I probably wouldn't download one."

The issue of only being interested in interacting with the library in the library, was also raised again, with one group concluding that there was no point in watching such materials on their mobile devices as there were "plenty of computers in the library" and they would prefer to watch them on the larger computer screens.

On a positive note, one student said "if it worked and helped me, I'd use it and show it to all my friends", bringing us back again to the importance of perceived usefulness for all these services. It seems that is we can persuade students that any of these services would be of concrete use to them, then they will be happy using them.

\subsection{QR Codes}

All the groups felt that these were too complicated and had too high barriers to use for them to be of widespread use, even though the only barrier is to install a free application onto almost any camera phone. It seems that unless they are convinced in advance of QR codes utility, then they will not install an application to try them.

Some illustrative comments included:

"Why bother?"

"I don't really think enough people can use them ... it's not really going to happen"

"Personally I saw it and didn't know what to do with it".

The only positive comments about QR codes were summed up by one short quote by a student, "They have potential, but...", with no groups feeling they were an accessible and useful enough service to be worth the Library spending time on.

\subsection{Bluetooth}

Comments about using Bluetooth in any way were overwhelmingly negative, with no students in any group thinking it was an appropriate medium to interact with the library, mainly due to only ever turning Bluetooth on when they want to carry 
out a specific task, such as exchanging information with friends or between devices.

"Most of the people I know never have Bluetooth turned on."

"I only turn it one if I want to exchange information..."

The most succinct comment summing up the feeling about Bluetooth, agreed by all members of a focus group was "Oh, no, that is horrible", suggesting that whatever services were offered using Bluetooth, they were unlikely to have a significant uptake.

\section{Conclusion and implications for practice}

There are always dangers in generalising results from one small study at an individual institution. However, the conclusions and implications for practice below are drawn from the qualitative data that should be readily transferable to other academic institutions where the context of mobile phone use is similar. This includes institutions across the UK, Europe, North America and Australasia. It is unlikely that the conclusions will be as relevant in areas where current mobile phone availability and use follows significantly different patterns, such as in most developing countries and in certain highly developed countries in Asia (such as Japan). The ordering of preference of individual services may well vary from institution to institution, but the general attitudes towards text messages and mobile web friendly services are likely to remain relatively constant with the general cultural environment of mass mobile phone use.

The students who participated in the focus groups confirmed some of the commercial research into the acceptance of text messaging contact. They were overwhelmingly positive about receiving text message based services from the Library, with the key caveat that they must believe that they are useful to them. This was confirmed in discussions about all the possible services, with perceived and obvious utility being the most important factor when deciding if they were interested in a service being developed. There was no sense of being willing to experiment and explore new services so they could discover for themselves which services would be useful.

They were also reluctant to use the mobile web, even when able to do so, though this may change in the near future as accessing the web via mobile phones becomes increasingly mainstream.

The results suggest that libraries considering increasing their services aimed at mobile users should:

a) Initially introduce services that use text messaging, not the mobile web.

b) Concentrate on services that potential users can immediately see benefits for, such as "reminders" of overdue books, rather than services with less obvious, or less mainstream benefits.

c) Make sure that any mobile friendly services are marketed carefully, selecting the groups most likely to benefit from them and directly stressing those benefits to the potential users in any promotional activities. 
This study qualitatively studied student attitudes to mobile friendly library services in general, rather than focussing on individual services being piloted or introduced by a library. This is unusual in the published literature and there is potential for more studies in this area, investigating what students would like developed, rather than whether new or existing services are working. It would also be beneficial to investigate if the current wariness of the mobile web by participants in this study is significantly reducing as smartphones increase their market penetration. Any such studies would help build a consensus towards the sort of mobile services we should be developing based on the attitudes and desires of our users, rather than the preferences of institutions and our funders.

\section{References}

Berk, J., Olsen, S., Atkinson, J., and Comerford, J. (2007). Innovation in a podshell: bringing information literacy into the world of podcasting. The electronic library, 25(4), 409-419.

Buczynski, J. (2008). Libraries begin to engage their menacing mobile phone hordes without shhhhh! Internet Reference Services Quarterly, 13(2-3), 261-269.

Hahn, J. (2008). Mobile learning for the twenty-first century librarian. Reference Services Review, 36(3), 272-288.

Herman, S. (2007). SMS reference: keeping up with your clients. The Electronic Library, 25(4), 401-408.

Karjaluoto, H. Leppäniemi, M. Standing, C. Kajalo, S. Merisavo, M. Virtanen, V. and Salmenkivi, S. (2006) Individual differences in the use of mobile services among Finnish consumers. International Journal of Mobile Marketing, 1(2), 4-10.

Karjaluoto, H. Standing, C. Becker, M. and Leppäniemi, M. (2008) Factors affecting Finnish consumers' intention to receive SMS marketing: a conceptual model and an empirical study. International Journal of Electronic Business, 6(4), 298-318.

Kim, S., Mims, C., and Holmes, K. (2006). An introduction to current trends and benefits of mobile wireless technology use in higher education. Association for the Advancement of Computing in Education Journal, 14(1), 77-100.

Merisavo, M. Kajalo, S. Karjaluoto, H. Virtanen, V. Salmenkivi, S. Raulas, M. and Leppäniemi, M. (2007) An empirical study of the drivers of consumer acceptance of mobile advertising. Journal of Interactive Advertising, 7(2), 1-18.

Pasanen, I. (2002) Around the world to Helsinki University of Technology: new library services for mobile users. Library Hi Tech News, 19(5), 25-28.

Jones, G. Edwards, G. Reid, A. (2008) Supporting and enhancing undergraduate learning with m-learning tools: an exploration and analysis of the potential of Mobile Phones and SMS. Proceedings of the 6th International Conference on Networked Learning, URL: http://www.networkedlearningconference.org.uk/past/nlc2008/abstracts/PDFs/Jon es_162-170.pdf [accessed 3.5.10]. 
Ronchetti, M., and Stevovic, J. (2008). Extending the podcasting approach: lectures on the phone. Paper presented at the Proceedings of World Conference on Educational Multimedia, Hypermedia and Telecommunications, 2008.

Sillence, E., and Baber, C. (2004). Integrated digital communities: combining web-based interaction with text messaging to develop a system for encouraging group communication and competition. Interacting with Computers, 16, 93-113.

Uday Bhaksar, N., and Govindarajulu, P. (2008). Implications of mobile phone technology usage on learners in a learning process. International Journal of Computer Science and Network Security, 8(5), 251-259.

Walsh, A. (2009) Text Messaging (SMS) and libraries. Library Hi Tech News, 26(8), 9-11.

\section{The Occasion}

This research was sponsored by the Library and Information Research Group's research award 2009 and the author thanks the group for their support.

\section{Open access and copyright}

Library and Information Research is an open access journal. A freely available copy of this paper may be downloaded from the journal's website:

http://www.cilipjournals.org.uk/lir

Copyright and associated moral rights in works published in Library and Information Research are retained by the author(s) but this paper may be used freely, with proper attribution, in educational and other non-commercial settings. 